\title{
Photodegradation of Gaseous Toluene by Vacuum Ultraviolet Light: Performance and Mechanism
}

Hao Yuan, ${ }^{1,2}$ He Peng, ${ }^{1}$ Jie Guan, ${ }^{1,2 *}$ Yong Liu, ${ }^{1}$ Jue Dai, ${ }^{1,2}$ Ruijing Su, ${ }^{1,2}$ Zhanhu Guo, ${ }^{3}$ Yun Chen, ${ }^{3}$ Qian Hu, Bingnan Yuan, ${ }^{3}$ Hongcheng Wu, ${ }^{1}$ Dan Kilula ${ }^{4}$ and Ilwoo Seok ${ }^{4 *}$

The degradation of volatile organic compounds using short wavelengths of ultraviolet is attractive to reduce chemical pollutants. This research focuses on the the photo-degradation of toluene, one of common volatile organic compounds that widely distributed in the environment, by experimental process using the irradiation of vacuum ultraviolet light. The performance and mechanism of the degradation process were systematically evaluated by changing core factors in experimental conditions: residence time, initial concentration, relative humidity, and degradation intermediates. Major finding was that the photo-degradation rate of toluene is inversely proportional to the concentration of toluene, on the other hand, proportional to the light intensity and relative humidity. This study also investigated the bond-dissociation energy of toluene under $185 \mathrm{~nm}$ wavelength of irradiation and its molar absorption coefficients. Finally, the pathway for photodegradation of toluene was developed with a diagram of the chemical flow. The results are useful toward the air pollution research and its management applications.

Keywords: Degradation pathways; Photo-degradation; Volatile organic compounds (VOC); Vacuum ultraviolet (VUV); Quantum chemistry

Received 2 February 2020, Accepted 17 February 2020

DOI: $10.30919 / \mathrm{es} 8 \mathrm{~d} 910$

\section{Introduction}

Among many problems that the world is currently facing, air pollution is undoubtedly one of the most important. According to the World Health Organization (WHO), about 7 million people have died due to air pollution related issues. Many harmful volatile organic compounds (VOCs) such as carcinogenic, mutagenic or teratogenic ${ }^{1,2}$ are contained in the air. These compounds are originated from the automobile exhaust, chemical plants, printing and spraying chemicals, factories, fossil fuels combustion, and so on. ${ }^{3}$ In addition, atmospheric photochemical reactions cause secondary organic aerosols that also contribute to ozone pollution. ${ }^{4,5}$ Since nondestructive technology with adsorption/absorption is unable to convert VOCs into non-toxic inorganic molecules, ${ }^{6}$ innovative and efficient processes have been required to destroy VOCs.

UV light is widely applied to degrade organic compounds in wastewater through the oxidative processes. ${ }^{7,8}$ In spite of significant improvements on catalytic oxidation of VOCs, the application is still limited to the photocatalytic deactivation, ${ }^{9-12}$ electron-hole pair recombination, ${ }^{13,14}$ and low UV utilization with a poor efficiency. ${ }^{15}$ Instead of expensive methods of using and maintaining catalysts, a non-catalytic approach for the degradation of VOCs comes with significant advantages.

Vacuum ultraviolet (VUV) degradation is a promising alternative technique for decomposing gaseous organic compounds. The degradation occurs by a combination of

\footnotetext{
${ }^{\prime}$ School of Environmental and Materials Engineering, Shanghai Second Polytechnic University, Shanghai 201209, China

${ }^{2}$ Research Center of Resource Recycling Science and Engineering, School of Environmental and Materials Engineering, Shanghai Second Polytechnic University, Shanghai 201209, China

${ }^{3}$ Department of Chemical and Biomolecular Engineering, University of Tennessee, Knoxville, TN 37996, USA

${ }^{4}$ College of Engineering and Computer Sciences, Arkansas State University, State University, AR 72467, USA

*E-mail: guanjie@sspu.edu.cn (J. Guan); iseok@astate.edu (I. Seok)
} 
photolysis and oxidation. Low-pressure mercury lamps with high-purity quartz emit dual-bands of UV light at 185 and 254 nm. ${ }^{6}$ The photons in $185 \mathrm{~nm}$ VUV have a higher energy (6.7 $\mathrm{eV}$ ) than $254 \mathrm{~nm}$. This energy is high enough to dissociate most organic compound bonds, target directly the organic bonds, and transform them into smaller molecule organic compounds. Furthermore, molecules of $\mathrm{O}_{2}$ and $\mathrm{H}_{2} \mathrm{O}$ in air absorb energetic photons and generate $\mathrm{O}_{3}, \mathrm{O}\left({ }^{1} \mathrm{D}\right)$ and $\bullet \mathrm{OH}$ radicals, ${ }^{6,16}$ which are highly energetic oxidizing species and contribute to the dissociation of VOCs. A mixture of $\mathrm{O}_{2}$ and $\mathrm{H}_{2} \mathrm{O}$ molecules with $254 \mathrm{~nm}$ of UV light are used to generate $-\mathrm{O}_{3}$ which is then applied to test an oxidative decomposition ${ }^{17}$ of another VOCs; naphthalene, ${ }^{18}$ benzene, ${ }^{19}$ and chlorinated methane. ${ }^{20}$ In this study, experiments were mainly focused on optimizing the parameters to improve the degradation efficiency. Since few researches on the mechanism of VOCs oxidation during the VUV process have been investigated, the question on the production of active species and its intermediate processes still remain. The main goal of this research was to investigate the degradation efficiency of toluene under different critical parameters; relative humidity $(\mathrm{RH})$, residence time, initial toluene concentration, and gas medium. In addition, the formation of the oxide species was studied to determine the mechanism for the degradation of toluene in the VUV process.

\section{Experimental Section}

\subsection{Chemicals and Experiment Instrument}

The chemicals used in this study included toluene solution, ethyl alcohol, methyl alcohol (chromatographic grade, SINOPHARM, China), high purity nitrogen, and high purity air (99.99\%, ChunYu Special Gas, China).

\subsection{Photoreactor for UV Sources}

To perform the experiment, a continuous flow photoreactor (Volume $=2.7$ liter) consisting of three UV lamps and a stainless-steel cylinder (140 $\mathrm{mm}$ in diameter, height $180 \mathrm{~mm}$ ) was used. As shown in Fig. 1, three UV lamps were equally spaced inside the reactor in a formation of an equilateral triangle. Two funnel-shaped airflow homogenizers were positioned at the inlet and outlet of the reactor to ensure a uniform airflow through the reactor. The three low-pressure mercury lamps (UV light and Electricity Co., Ltd, China) were characterized by the emission of dual bands at $185 \mathrm{~nm}$ (approximately 7\%) and $254 \mathrm{~nm}$ with the UV irradiation. The electric power output of three UV lamps was approximately 54 W.

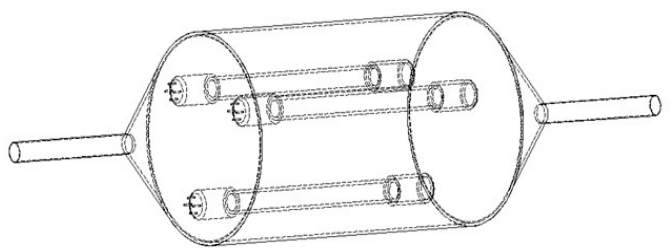

Fig. 1 VUV photoreactor with three mercury UV lamps.

Table 1 List of chemicals and specifications.

\begin{tabular}{cccc}
\hline Chemicals & Formula & Purity & Manufacturer \\
\hline Toluene & $\mathrm{C}_{7} \mathrm{H}_{8}$ & Analytical pure & Sinophram \\
Ethanol & $\mathrm{C}_{2} \mathrm{H}_{6} \mathrm{O}$ & Analytical pure & Sinophram \\
Methanol & $\mathrm{CH}_{4} \mathrm{O}$ & Chromatographically pure & Sinophram \\
High purity air & -- & $99.99 \%$ & Shanghai Chunyu Special Gas \\
High purity nitrogen & $\mathrm{N}_{2}$ & $99.99 \%$ & Shanghai Chunyu Special Gas \\
\hline
\end{tabular}

Table 2 List of experiment instrumentation.

\begin{tabular}{cccc}
\hline NO. & Experimental facility & Manufacturer & Model \\
\hline 1 & GC & Shimadzu & $2014 \mathrm{C}$ \\
2 & GC-MS & Agilent & $7890 \mathrm{~B}$ \\
3 & Mass flowmeter & Beijing Sevenstar Electronics & CS200-A \\
4 & Air pump & Denair & -- \\
5 & Portable Thermo-hygrometer & Hanna instruments & HI9565 \\
6 & Anemometer & Fluke & FLUKE-923 \\
\hline
\end{tabular}




\subsection{Experimental Procedure}

For experimentation, toluene was selected as the pollutant volatile organic compound. The sample toluene gas was extracted from pure liquid toluene inside an ice water bath of $0{ }^{\circ} \mathrm{C}$. The concentration of toluene was controlled by mixing vaporized toluene with dry clean air. The targeted relative humidity $(\mathrm{RH})$ was controlled by the approach same as the one used for the gaseous toluene. Mass flow controllers (Beijing Sevenstar Flow Co., Ltd, CS200) were used to permanently regulate the fluidity of the gas. All the gas tubes used in the experiment were made out of polytetrafluoroethylene. The reaction temperature was set at constant temperature of $25 \pm 2{ }^{\circ} \mathrm{C}$. The UV lamp was switched on 30 minutes after the concentrations in the inlet and outlet reached the same level. The range of experimental values for toluene concentration, $\mathrm{RH}$, and residence time were set to 5 - 40 ppmv, 0 - 99\%, and 5 - 10 s, respectively. Fig. 2 demonstrates the experimental setup of apparatus.

\subsection{Analysis}

The sample toluene concentrations were manually collected and measured with a gas chromatograph (GC-2014C, Shimadzu Co. Ltd.) as well as a hydrogen flame ionization detector. A $100 \mathrm{~mL}$ glass syringe was used to collect sample and the injection was quantified with a loop of $1 \mathrm{~mL}$. The $\mathrm{RH}$ and temperature at the inlet and outlet were measured by a thermohydrometer (HANNA instrument Co. Ltd, HI9565). The degradation intermediates of toluene from the reactor outlet were collected in sampling bags, and subsequently analyzed with a Gas Chromatography-Mass Spectrometer (Agilent-7890B Shanghai asicotech Co., Ltd, P7000) that was equipped with the automatic sampler, an EI ion source (electron energy $70 \mathrm{eV}$ ), and an electron multiplier detector that enabled to record ions from $\mathrm{m} / \mathrm{z}$ equal to 10 - 300. The parameters that the chromatographic mass spectrometer used were; a temperature set at $50{ }^{\circ} \mathrm{C}$ for initial 10 minutes, then increased to $250{ }^{\circ} \mathrm{C}$ with an increment of $10^{\circ} \mathrm{C}$ per min, the full scan mode, and a 30450 of mass range. The model of American Agilent HP-AL/ $\mathrm{S}$ column was used, and the analyzed map of results was compared with the NIST14 database. The degradation efficiency of toluene was calculated by measuring the concentration of toluene from the inlet and outlet, with the following formula.

$$
\eta=\frac{C_{\text {in }}-C_{\text {out }}}{C_{\text {in }}} \times 100[\%]
$$

where $\eta$ represents degradation efficiency of toluene and $C_{\text {in }}$ and $C_{\text {out }}$ are the toluene's concentrations at inlet and outlet.

\section{Results and Discussion}

\subsection{Effect of Experimental Conditions on Degradation Efficiency}

Resident time: The flow rate was adjusted by using a mass flow meter with $67.2,33.6,21,16.8$ and $11.5 \mathrm{liter} / \mathrm{min}$. The conditions of gas $\mathrm{RH}$ and initial toluene concentration were $60 \%$ and 10 ppm respectively, under the initial power of 54 $\mathrm{W}$ in a UV lamp. The degradation efficiency increased from $63 \%$ to $92 \%$ as the residence time increased from 2.5 to 15 s. This complies with the findings of Huang and collaborators. ${ }^{21}$ The longer residence time allowed $\mathrm{O}_{2}, \mathrm{H}_{2} \mathrm{O}$ and toluene to have more collision with high-energized photons from the VUV lamps. The amount of toluene degradation was lessened with increasing the residence time due to the dropping of UV utilization. The existence differences between degradative amount and efficiency
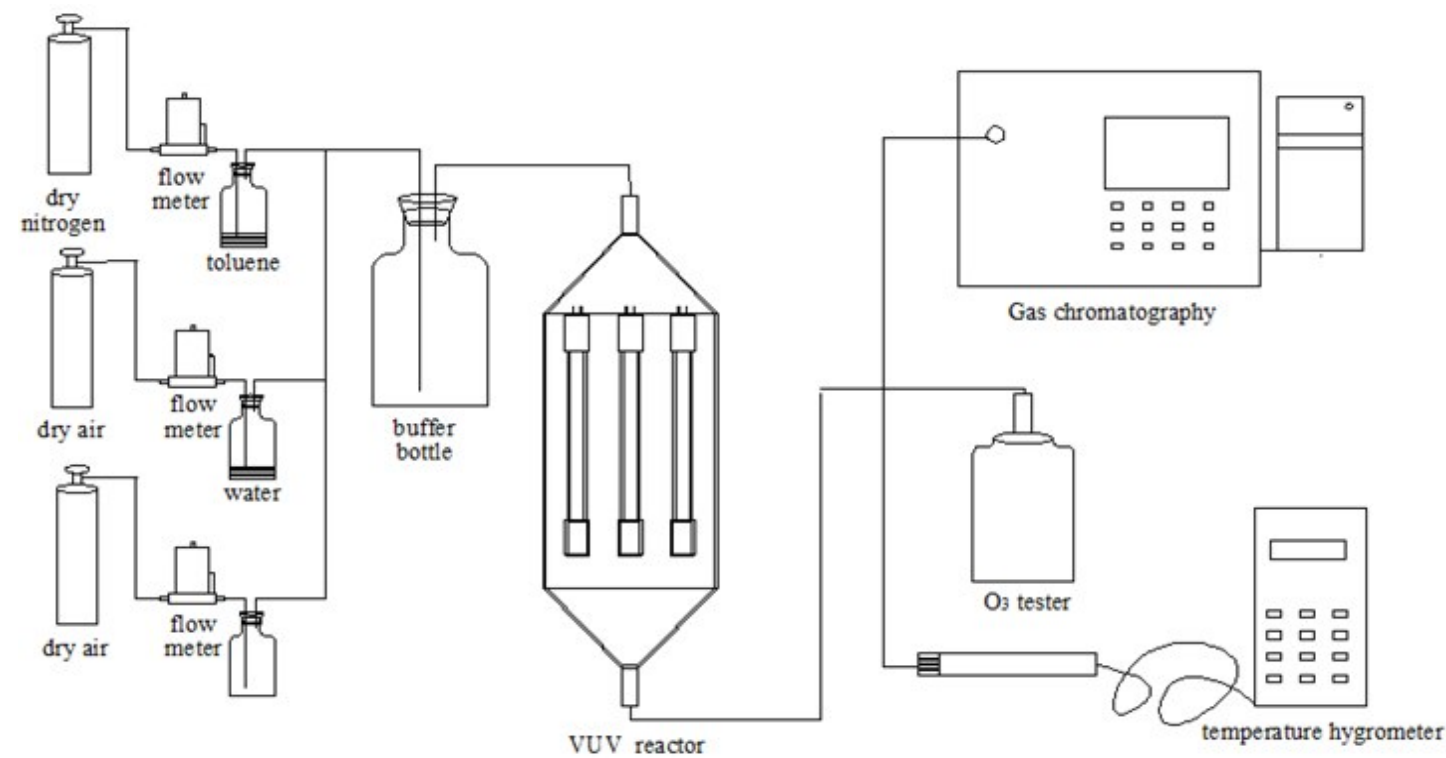

Fig. 2 Schematic diagram of the experimental apparatus. 

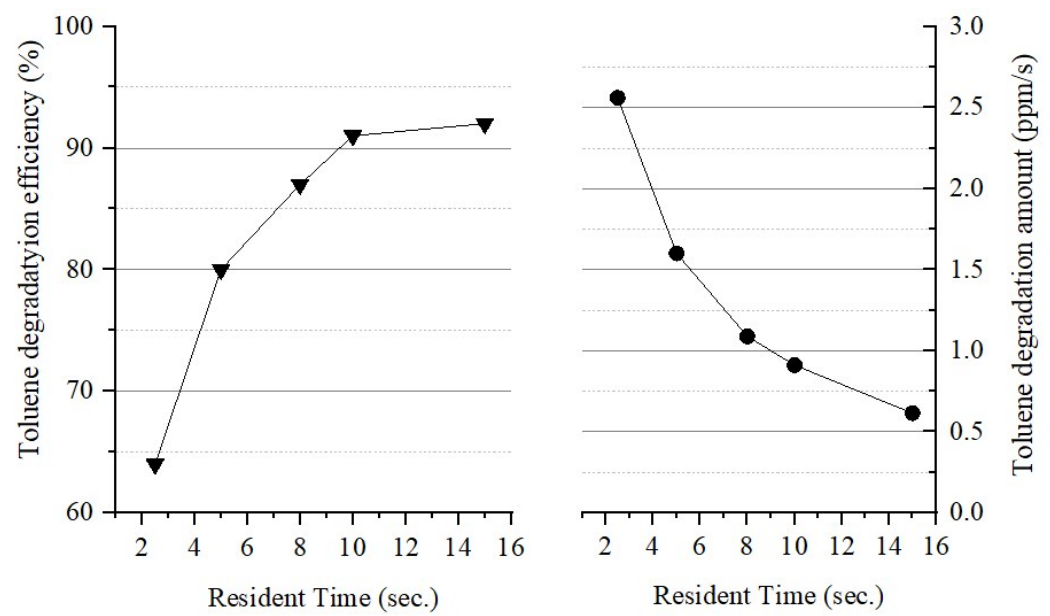

Fig. 3 Effect of resident time on the toluene degradation efficiency (left) and amount of toluene under vacuum ultraviolet (right).

could be attributed to the collision efficiency of photons with toluene molecules. Fig. 3 shows the results of the inverse relationship between the degradation efficiency and degradation amount.

Initial toluene concentration: To study the effect of the initial concentration of toluene, gaseous RH was fixed at $60 \%$ and the residence time at 5 seconds. The research investigated the effect of the initial toluene concentration with conditions of 5 to $40 \mathrm{ppm}$ and 18,36 and $54 \mathrm{~W}$ of the power of UV lamp. At $18 \mathrm{~W}$, the degradation was significantly reduced, going from $74.46 \%$ to $21.67 \%$. However, at a higher power of $54 \mathrm{~W}$, the degradation efficiency decreased from $92.85 \%$ to $71.51 \%$. Less collision of high-energized photons with toluene and insufficient oxidant caused the decrease of degradation efficiency of toluene.

However, the curve of toluene degradation amount had a completely different trend from the removal efficiency. As shown in Fig. 4 (right), under the irradiation of $18 \mathrm{~W} \mathrm{UV}$ lamp, toluene degradation amount increased obviously with the increase of the toluene initial concentration from $5 \mathrm{ppm}$ to $10 \mathrm{ppm}$, the amount of removed toluene almost did not increase as the initial toluene concentration was increased from 10 to $50 \mathrm{ppm}$. This result believed indicated that scant production of energetic photons and active oxidants reduced toluene degradation efficiency and UV lamp utilization reached its maximum. Under the irradiation of $36 \mathrm{~W}$ or 54 W UV lamp, the amount of removed toluene increased sharply as the initial toluene concentration increased. Under the irradiation of sufficient power VUV lamp, toluene molecules absorbed more high-energy photons to photolysis. $\mathrm{O}_{2}$ and $\mathrm{H}_{2} \mathrm{O}$ in air also absorbed more highenergy photons to generate hydroxyl radicals, $\mathrm{O}_{3}$. Thus, the amount of removed toluene practically linear increased with toluene initial concentration increasing.
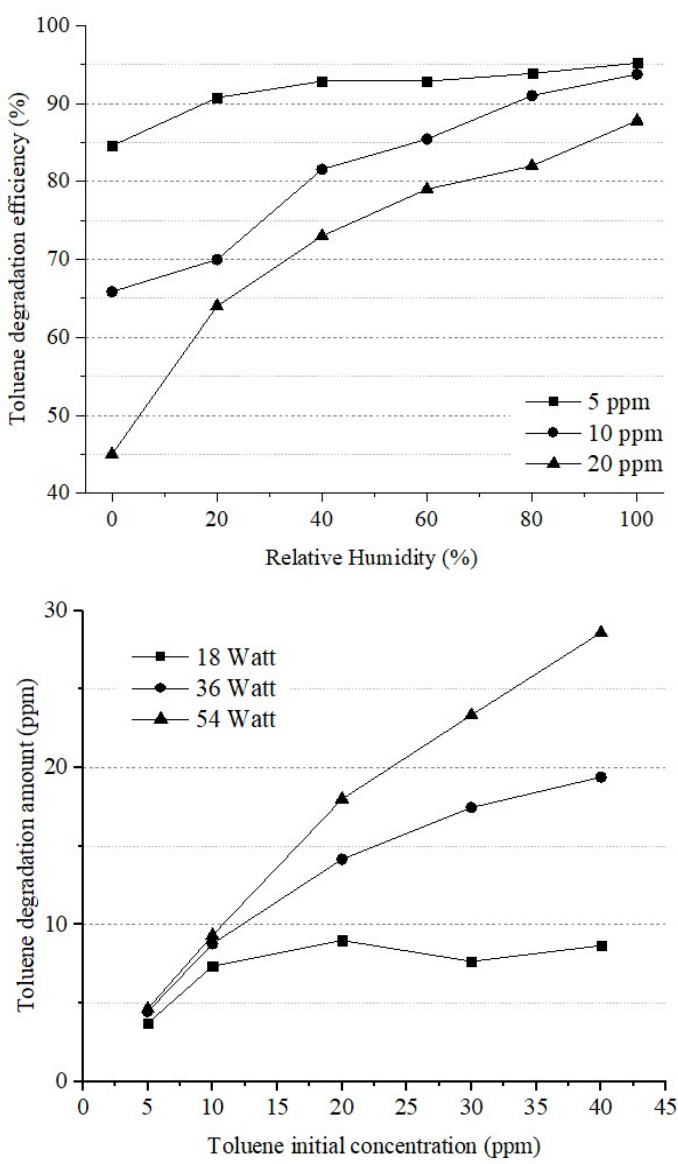

Fig. 4 Effect of initial toluene concentration (left) and relative humidity (right) on degradation efficiency of toluene under VUV photodegradation.

Gas relative humidity (RH): Fig. 4 (right) shows the result of the degradation as a function of relative humidity $(\mathrm{RH})$ in the range of $0-99 \%$. To evaluate the effect of the $\mathrm{RH}$, the experiments were executed with fixed values of a $\mathrm{RH}$ of $60 \%$ for the toluene, a residence time of $5 \mathrm{~s}$ and $54 \mathrm{~W}$ of lamp power, but varying an initial toluene concentration of 5, 10, and 
$20 \mathrm{ppm}$. The results indicate that the RH of the gas plays an important role in the toluene photo-degradation. Furthermore, it explains that water vapor contributes to an additional oxidative pathway by a hydroxyl radical. When the toluene was set at $20 \mathrm{ppm}$, the toluene conversion efficiency was only $45 \%$ in dry clean air, whereas at RH $99 \%$ of the toluene conversion efficiency reached $87.7 \%$. Consecutively, with the initial concentration of toluene of $10 \mathrm{ppm}$, the toluene photodegradation efficiency was $65.8 \%$ in a dry clean air, and $93.7 \%$ in a $\mathrm{RH}$ of $99 \%$. Possible pathways of hydroxyl radical formation in VUV processes were as follows:

$$
\mathrm{H}_{2} \mathrm{O}+\mathrm{hv} \rightarrow \cdot \bullet \mathrm{OH}+\cdot \mathrm{H} \mathrm{H}_{2} \mathrm{O}+\mathrm{O}\left({ }^{1} \mathrm{D}\right) \rightarrow 2 \cdot \mathrm{OH}
$$

The increase in toluene degradation efficiency with $\mathrm{RH}$ does not occur in the photocatalytic process. Toluene degradation efficiency increased initially and then decreased as the RH increased in the photocatalytic process and this was attributed to excess water molecules inhibiting the active site of the photocatalyst. ${ }^{21}$

Gas medium: Four different reaction media; dry nitrogen stream, dry air stream, nitrogen stream with $60 \% \mathrm{RH}$, and an air stream with $60 \% \mathrm{RH}$, were utilized to determine their contribution to the possible pathways and advanced oxide species of toluene oxidation. Conversion efficiency of toluene in dry nitrogen stream with $15.37 \%$ shows that only photolysis of toluene is able to react. Since nitrogen does not absorb 185 and $254 \mathrm{~nm}$ wavelengths of $\mathrm{UV}$ light, no $\mathrm{H}_{2} \mathrm{O}$ and oxygen exist in the dry nitrogen, therefore none of $\bullet \mathrm{O}$ and $\bullet \mathrm{OH}$ are involved in the oxidation of toluene. It is concluded that the conversion of toluene was attributed solely to the photolysis in the dry nitrogen stream. On the other hand, in nitrogen stream with $60 \% \mathrm{RH}$, the conversion efficiency raised to $68.75 \%$. To verify the contribution of $\bullet \mathrm{OH}$, an experiment was performed at $60 \%$ $\mathrm{RH}$ in a nitrogen stream, with no oxygen. In addition, uniquely dry air stream was used to examine the contribution of $\bullet \mathrm{O}$. The findings were that the toluene conversion was unrelated to water and hence $\cdot \mathrm{OH}$, with a constant efficiency of $31 \%$. After subtracting the photolysis, it can be inferred, $15-63 \%$ toluene was oxidized by $\bullet$ O. Additionally, the conversion was $87.77 \%$ in air stream with $60 \% \mathrm{RH}$. Noticeably, $\bullet \mathrm{OH}$ was the dominant species leading to toluene conversion under VUV radiation.

\subsection{Degradation Pathways of Toluene Conversions in VUV Process}

Many researches have proposed a mechanism for the photocatalytic oxidation of toluene. ${ }^{14,16,22}$ However, few researchers demonstrated the mechanism of VUV photolysis of toluene and the source of oxides. Toluene conversion under VUV irradiation has two pathways: (1) Destruction of toluene by energetic photons under $185 \mathrm{~nm}$ wavelength, (2) Oxidation by hydroxyl radicals $(\cdot \mathrm{OH})$ and reactive oxygen species $\left(\mathrm{O}_{3}\right.$, $\left.\mathrm{O}\left({ }^{1} \mathrm{D}\right)\right)$.

Photolysis of toluene: The Grotthuss - Draper law ${ }^{23}$ states that photolysis occurs under two necessary conditions: high energy excited enough to break the chemical bond in the molecules and the light absorption for photochemistry.

The spectrum of a mercury discharge lamp has two lines of intensive resonance at 254 and $185 \mathrm{~nm}$. Gaseous toluene has continuous peaks of characteristic absorption in the ultraviolet spectrum. Serralheiro et al. ${ }^{17}$ measured gaseous toluene electronic spectroscopy in the 4.0-10.8 eV energy range and demonstrated that gaseous toluene absorbed both at 254 and $185 \mathrm{~nm}$. The $185 \mathrm{~nm}$ photon energy is $647 \mathrm{~kJ} / \mathrm{mol}$, which is bigger than the dissociation energy of $\mathrm{C}-\mathrm{C}$ bond in the benzene and methyl $(424.9 \mathrm{~kJ} / \mathrm{mol})$ and in aromatic ring $(583.3 \mathrm{~kJ} / \mathrm{mol})$. Thus, $185 \mathrm{~nm}$ VUV photons can directly attack the phenylmethyl or the benzene ring. On the other hand, photon energy at $254 \mathrm{~nm}$ is low $(471 \mathrm{~kJ} / \mathrm{mol})$ and insufficient for toluene conversion. Water vapor and oxygen absorb higher energy photons than toluene due to the concentration. According to the second law of photochemistry of StarkEinstein, molecules have photochemical reactions with

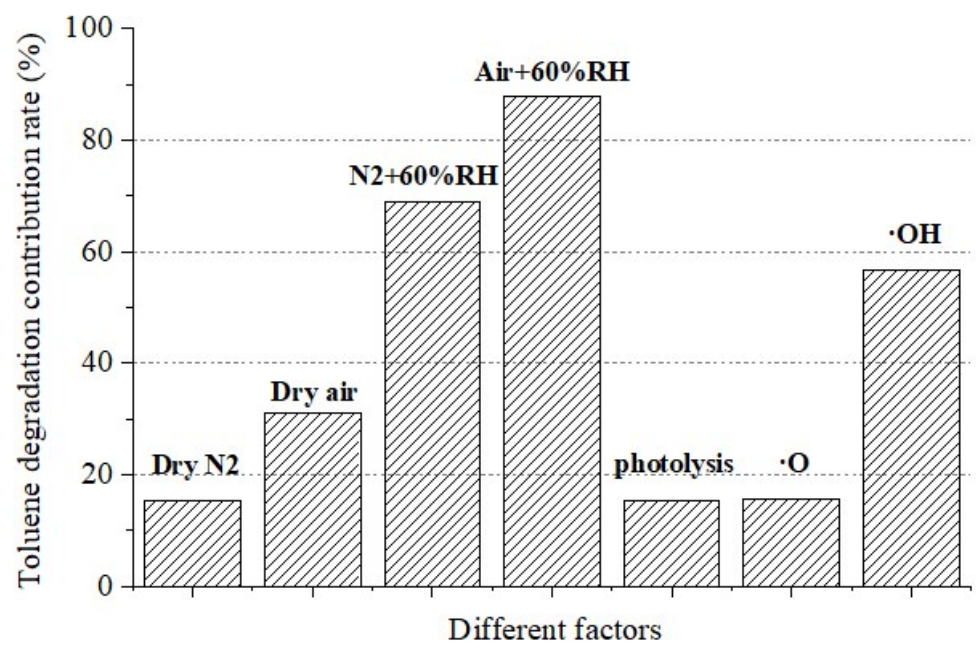

Fig. 5 Effect of different gas medium on degradation efficiency. 
molecules one by one basis. This implies that the toluene's efficiency by photolysis is smaller than those of water and oxygen.

Formation of oxygen species and oxidation of toluene: In the VUV process for the degradation of toluene, oxygen is one of core oxidants and the species such as $\mathrm{O}_{3}, \mathrm{O}\left({ }^{1} \mathrm{D}\right)$, and $\mathrm{O}$ $\left({ }^{3} \mathrm{P}\right)$ may be produced under the radiation of low-pressure mercury lamps as follows:

$$
\begin{gathered}
\mathrm{O}_{2}+\mathrm{hv}(185 \mathrm{~nm}) \rightarrow \mathrm{O}\left({ }^{1} \mathrm{D}\right)+\mathrm{O}\left({ }^{3} \mathrm{P}\right) \\
\mathrm{O}\left({ }^{1} \mathrm{D}\right)+\mathrm{M} \rightarrow \mathrm{O}\left({ }^{3} \mathrm{P}\right)+\mathrm{M}\left(\mathrm{M}=\mathrm{O}_{2} \text { or } \mathrm{N}_{2}\right) \\
\mathrm{O}\left({ }^{3} \mathrm{P}\right)+\mathrm{O}_{2}+\mathrm{M} \rightarrow \mathrm{O}_{3}+\mathrm{M} \\
\mathrm{O}_{3}+\mathrm{hv}(254 \mathrm{~nm}) \rightarrow \mathrm{O}\left({ }^{1} \mathrm{D}\right)+\mathrm{O}_{2} \\
\mathrm{O}\left({ }^{1} \mathrm{D}\right)+\mathrm{H}_{2} \mathrm{O} \rightarrow 2 \cdot \mathrm{OH}
\end{gathered}
$$

The pathways for the $\mathrm{O}\left({ }^{1} \mathrm{D}\right)$ formation are: (1) O-O bond dissociation energy of $5.12 \mathrm{eV}$, and the molar absorption coefficient of oxygen at $185 \mathrm{~nm}$ wavelength is $36 \mathrm{~mol} / \mathrm{dm}^{3}$. In this environment,energetic photons with $\mathrm{O}_{2}$ gas molecules are more likely to occur, resulting in active species $\mathrm{O}\left({ }^{1} \mathrm{D}\right)$. (2) Ozone decomposition at $254 \mathrm{~nm}$ produces $\mathrm{O}\left({ }^{1} \mathrm{D}\right)$. The energy for photodissociation of oxygen and then generating one $\mathrm{O}\left({ }^{1} \mathrm{D}\right)$ or two $\mathrm{O}\left({ }^{1} \mathrm{D}\right)$ radicals is $683 \mathrm{~kJ} / \mathrm{mol}$ or $873 \mathrm{~kJ} / \mathrm{mol}$, which is larger than the energy of photons in $185 \mathrm{~nm}$ wavelength. Ozone decomposition to generate $\mathrm{O}\left({ }^{1} \mathrm{D}\right)$ requires $291 \mathrm{~kJ} / \mathrm{mol}$, which is smaller energy, and thus, the main formation pathway of $\mathrm{O}$ $\left({ }^{1} \mathrm{D}\right)$ is ozone decomposition.

Huang et al. ${ }^{16}$ reported that $\mathrm{O} \bullet$ is able to oxidize toluene by the abstraction of two hydrogen atoms from the methyl group and produce benzaldehyde and no benzyl alcohol. Benzaldehyde is then oxidized to benzoic acid or other organic compounds. Without the involvement of hydroxyl radicals, toluene with oxygen radicals of $\mathrm{CO}_{2}$ and $\mathrm{H}_{2} \mathrm{O}$ is not oxidized straightforwardly. In this study, the final gas component was tested by GC-MS and benzyl alcohol was not detected, which is same line with the literature. ${ }^{16}$

Due to fast recombination, lifetime of $\mathrm{O}\left({ }^{1} \mathrm{D}\right)$ is only few microseconds (about $10^{-9} \mathrm{~s}$ ) at atmospheric pressure ${ }^{24}$ and most $\mathrm{O}\left({ }^{1} \mathrm{D}\right)$ are rapidly converted to $\mathrm{O}\left({ }^{3} \mathrm{P}\right)$ by colliding with $\mathrm{N}_{2}$ or $\mathrm{O}_{2}$. Only part of $\mathrm{O}\left({ }^{1} \mathrm{D}\right)$ contributes to the formation of $\cdot \mathrm{OH}$ by reacting with $\mathrm{H}_{2} \mathrm{O}$. The chemical reaction rate of toluene's $\mathrm{O}$ $\left({ }^{1} \mathrm{D}\right)$ oxidation is only $7.6 \times 10^{-14}$ molecule $\mathrm{cm}^{-3} \mathrm{~s}^{-1}$. The ozone oxidation of toluene reaction rate is slower than $\mathrm{O}(1 \mathrm{D})$ with only $3.9 \times 10^{-22}$ molecule $\mathrm{cm}^{-3} \mathrm{~s}^{-1}$. Huang et al. ${ }^{16}$ proved that ozone hardly reacts with toluene only and thus, oxygen species had little contribution to the VUV photodegradation process of toluene.

Formation of $\mathrm{OH}$ radicals and oxidation of toluene: $\mathrm{OH}$ radicals were produced from the photolysis of $\mathrm{H}_{2} \mathrm{O}$ at 185 $\mathrm{nm}$. The dissociation energy of $\mathrm{O}-\mathrm{H}$ bonds in $\mathrm{H}_{2} \mathrm{O}$ is $499.1 \mathrm{~kJ} /$ mol and the energy from $185 \mathrm{~nm}$ photons exceeds this value. $\mathrm{H}_{2} \mathrm{O}$ has a continuous spectrum between 175 and $190 \mathrm{~nm}^{25-27}$ and the molar absorption coefficient of $\mathrm{H}_{2} \mathrm{O}$ at $185 \mathrm{~nm}$ is only $19 \mathrm{~mol} / \mathrm{dm}^{3}{ }^{20}$ Thus, the pathway of $\mathrm{OH}$ radical production from photolysis $\mathrm{H}_{2} \mathrm{O}$ is not dominant. In addition, reaction of $\mathrm{O}\left({ }^{1} \mathrm{D}\right)$ with $\mathrm{H}_{2} \mathrm{O}$ produces $\mathrm{OH}$ radical. We explained that VUV process could produce a large number of $\mathrm{O}\left({ }^{1} \mathrm{D}\right)$. Reaction rate constant of $\mathrm{O}\left({ }^{1} \mathrm{D}\right)$ with $\mathrm{H}_{2} \mathrm{O}$ is $2.2 \times 10^{-10} \mathrm{~cm}^{3} /(\mathrm{mol} \cdot \mathrm{s})^{28-30}$ and this is the main formation pathway generating $\mathrm{OH}$ radicals.

$$
\mathrm{O}\left({ }^{1} \mathrm{D}\right)+\mathrm{H}_{2} \mathrm{O} \rightarrow 2 \cdot \mathrm{OH} \quad \mathrm{H}_{2} \mathrm{O}+\mathrm{hv} \rightarrow \cdot \mathrm{OH}+\mathrm{H} \bullet
$$

\begin{tabular}{|c|c|c|c|}
\hline material & reaction & $\begin{array}{l}\text { reaction rate constant } \\
\mathrm{cm}^{3} \cdot \text { molecule }^{-1} \mathrm{~s}^{-1}\end{array}$ & $\Delta \mathrm{H} / \mathrm{kJ} \cdot \mathrm{mol}^{-1}$ \\
\hline \multirow{8}{*}{$\mathrm{O}_{2}$} & $\mathrm{O}_{2}+\mathrm{hv} \rightarrow \mathrm{O}\left({ }^{3} \mathrm{P}\right)+\mathrm{O}\left({ }^{3} \mathrm{P}\right)$ & - & 494 \\
\hline & $\mathrm{O}_{2}+\mathrm{hv} \rightarrow \mathrm{O}\left({ }^{1} \mathrm{D}\right)+\mathrm{O}\left({ }^{3} \mathrm{P}\right)$ & - & 683 \\
\hline & $\mathrm{O}_{2}+\mathrm{hv} \rightarrow \mathrm{O}\left({ }^{1} \mathrm{D}\right)+\mathrm{O}\left({ }^{1} \mathrm{D}\right)$ & - & 873 \\
\hline & \multirow{2}{*}{$\mathrm{O}\left({ }^{1} \mathrm{D}\right)+\mathrm{M} \rightarrow \mathrm{O}\left({ }^{3} \mathrm{P}\right)+\mathrm{M}\left(\mathrm{M}=\mathrm{O}_{2}\right.$ or $\left.\mathrm{N}_{2}\right)$} & $4 \times 10^{-11}\left(\mathrm{M}=\mathrm{O}_{2}\right)$ & \\
\hline & & $2.6 \times 10^{-11}\left(\mathrm{M}=\mathrm{N}_{2}\right)$ & \\
\hline & \multirow[t]{2}{*}{$\mathrm{O}\left({ }^{3} \mathrm{P}\right)+\mathrm{O}_{2}+\mathrm{M} \rightarrow \mathrm{O}_{3}+\mathrm{M}$} & $6 \times 10^{-34}\left(\mathrm{M}=\mathrm{O}_{2}\right)$ & \\
\hline & & $5.6 \times 10^{-34}\left(\mathrm{M}=\mathrm{N}_{2}\right)$ & \\
\hline & $\mathrm{O}_{3}+\mathrm{hv} \rightarrow \mathrm{O}\left({ }^{1} \mathrm{D}\right)+\mathrm{O}_{2}$ & & 291 \\
\hline \multirow[t]{2}{*}{$\mathrm{H}_{2} \mathrm{O}$} & $\mathrm{O}\left({ }^{1} \mathrm{D}\right)+\mathrm{H}_{2} \mathrm{O} \rightarrow 2 \cdot \mathrm{OH}$ & $2.2 \times 10^{-10}$ & \\
\hline & $\mathrm{H}_{2} \mathrm{O}+h v \longrightarrow \cdot \mathrm{OH}+\mathrm{H} \bullet$ & - & 499.1 \\
\hline \multirow[t]{3}{*}{ Toluene } & $\cdot \mathrm{OH}+$ toluene $\rightarrow$ products & $5.96 \times 10^{-12}$ & \\
\hline & $\mathrm{O}_{3}+$ toluene $\longrightarrow$ products & $3.9 \times 10^{-22}$ & \\
\hline & $\mathrm{O}\left({ }^{1} \mathrm{D}\right)+$ toluene $\longrightarrow$ products & $7.6 \times 10^{-14}$ & \\
\hline
\end{tabular}

Effective factors to form $\mathrm{OH}$ radicals are VUV lamp power, RH, and residence time. Increasing power of VUV lamp leads the photochemistry stronger and improved formation of

Table 3 List of reaction and reaction rate constant in VUV process. 
$\mathrm{O}\left({ }^{1} \mathrm{D}\right), \mathrm{O}_{3}$, and $\mathrm{OH}$ radicals. The high $\mathrm{RH}$ increases light absorption at $185 \mathrm{~nm}$ and then produces more $\mathrm{OH}$ radicals from $\mathrm{H}_{2} \mathrm{O}$ photolysis or $\mathrm{O}\left({ }^{1} \mathrm{D}\right)+\mathrm{H}_{2} \mathrm{O}$. The residence time determines the probability of collision of gas molecules with high-energy photons and its increase would be beneficial to the formation of more $\mathrm{OH}$ radicals.

The $\mathrm{OH}$ radical is the essential atmospheric oxidant and dominates toluene's oxidation in the VUV process as demonstrated in the previous section. Many efforts have been made to explore the reaction of the $\mathrm{OH}$ radical with toluene. Wu et al. ${ }^{31}$ confirmed that the experimental results supporting a theoretical model of the $\mathrm{OH}$ radical oxidation of toluene. Trost et al. ${ }^{32}$ tested reactions of the $\mathrm{OH}$ radical with toluene and found that the reaction rate of $\mathrm{OH}$ radical with toluene is 5.96 $\times 10^{-12}$ molecules $\mathrm{cm}^{-3} \mathrm{~s}^{-1}$ at room temperature. This reaction rate is much larger than the reaction rate of $\mathrm{O}\left({ }^{1} \mathrm{D}\right)$ or $\mathrm{O}_{3}$ with toluene. The residence time of the gas in the reactor was only a few seconds, implying that the hydroxyl radical is the dominant contributor to the attack of toluene in the VUV process. Hydroxyl radicals react with toluene to form numerous intermediates, which were difficult to be captured and detected experimentally.

Hydroxyl radicals destroy toluene via two pathways: the addition reaction and hydrogen abstraction reaction. Wu et al. ${ }^{31}$ deemed that $93 \%$ of hydroxyl radicals reacted with toluene in addition to the aromatic, and only $7 \%$ as $\mathrm{H}$-abstraction from the $-\mathrm{CH}_{3}$ group. Intermediate product of the hydroxyl radical was not detected as well as toluene addition. An explanation might be the implication of to the strong vacuum used during the ultraviolet radiation. Due to the presence of high energy photons, the production of benzaldehyde and benzene was distinguished.

Pathways of toluene degradation in different gas environments: For the study of degradation of toluene in different gas conditions, three different gaseous media were used:dry nitrogen, humidified nitrogen, and aqueous air. Also, $10 \mathrm{ppm}$ of toluene, $54 \mathrm{~W}$ of UV lamp, $60 \%$ of gas RH, and 5 seconds of residence time in the reactor were applied as the experimental setup. The sampling was performed by using the air bag method. The products from toluene degradation were detected with a GC-MS. Afterwards, the test results were compared with the NIST14 library. The result data are shown in Fig. 6-8 below.

As shown in Fig. 6, only benzene was detected in the exhaust gas along with the undegraded toluene and a small amount of carbon dioxide. According to previous studies, ${ }^{33}$ toluene can be dehydrogenated under $185 \mathrm{~nm}$ UV irradiation to produce a benzyl group. However, nitrogen cannot be absorbed by $185 \mathrm{~nm}$ because of its higher dissociation energy of the nitrogen-nitrogen triple bond than the photon energy of $185 \mathrm{~nm}$. The resulting benzyl group has no other functional groups bonded thereto, and thus difficult to prove whether or not a benzyl group is produced. The dissociation energy of the $\mathrm{C}-\mathrm{C}$ bond of the benzene ring and the methyl group in toluene is $4.4 \mathrm{eV}$. The energy, smaller than the UV photon energy of 6.7 $\mathrm{eV}$, is directly demethylated to form benzene.

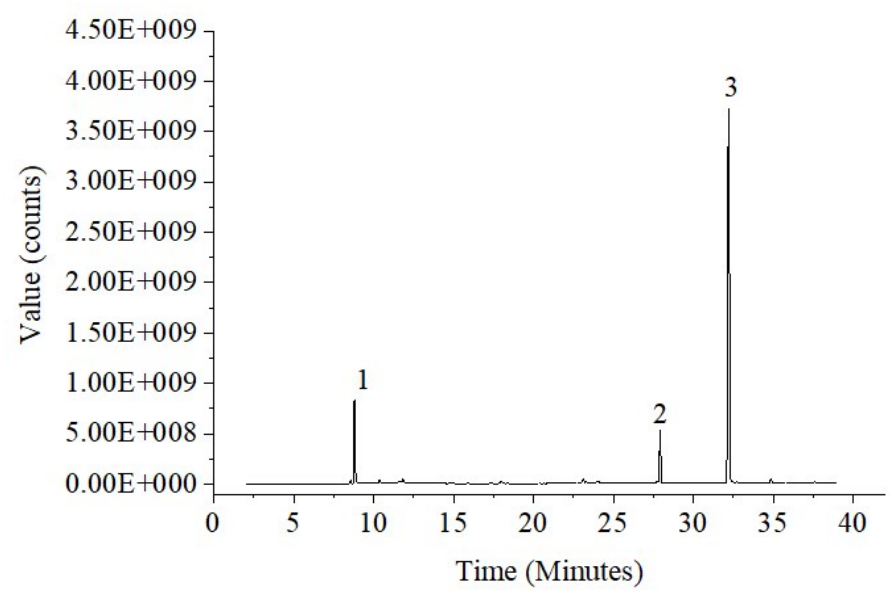

Fig. 6 Total nitrogen flow pattern of dry nitrogen: $1-\mathrm{CO}_{2} ; 2-$ benzene; 3-toluene.

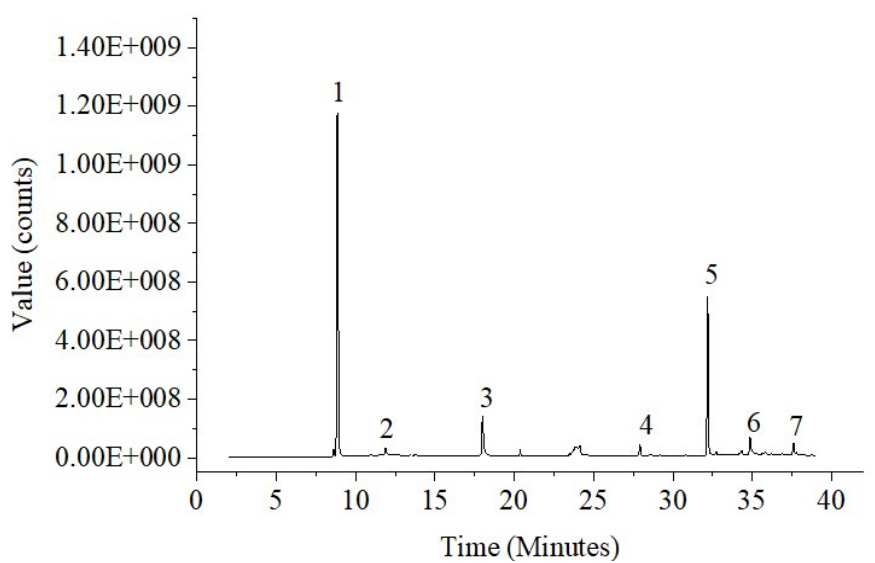

Fig. 7 Total ion flow diagram of aqueous nitrogen: $1-\mathrm{CO}_{2} ; 2-$ formaldehyde; 3-acetone; 4-benzene; 5-toluene; 6-column bleeding; 7-benzaldehyde.

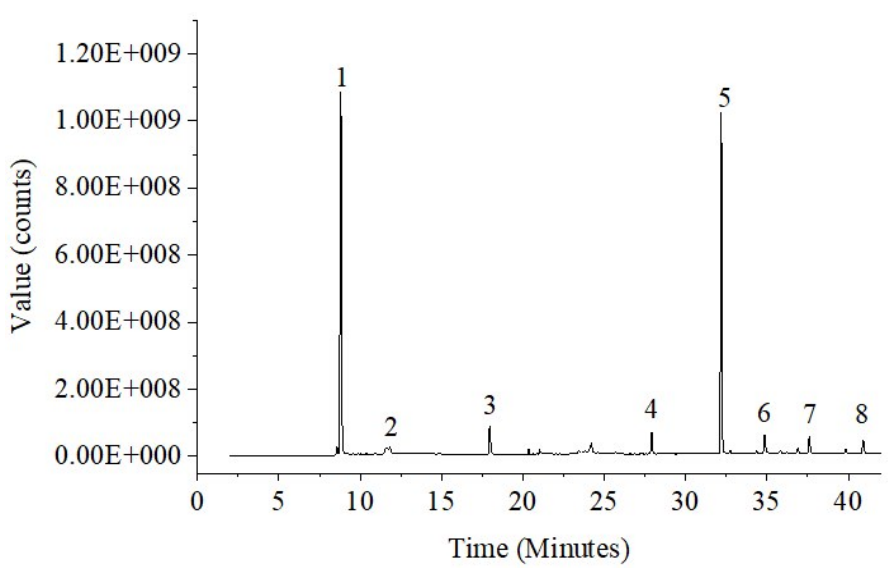

Fig. 8 Total ion flow diagram of aqueous air: 1- $-\mathrm{CO}_{2} ; 2-$ formaldehyde; 3-acetone; 4-benzene; 5-toluene; 6-column bleeding; 7-benzaldehyde; 8-benzoic acid 
Fig. 7 shows the generation of intermediate products under aqueous nitrogen: benzene, formaldehyde, acetone, and benzaldehyde. Since nitrogen cannot be destroyed by $185 \mathrm{~nm}$ UV light absorption, the hydroxyl radical is generated by water photolysis and the direct degradation of toluene may be in two ways of degradation under aqueous nitrogen. Compared to the results in Fig. 8, under the conditions of water participation, the amount of production of $\mathrm{CO}_{2}$ increased significantly, indicating an increased rate of mineralization. Wu et al..$^{31}$ suggested that the reaction modes of hydroxyl radicals and toluene are based on the dehydrogenation and addition reaction. The addition reaction is the main mode according to the previous work by Atkinson et al..$^{34}$ and supports this work. However, when highenergy photons and hydroxyl radicals work together, the result becomes different, showing that only hydroxyl radicals react with toluene. In the absence of oxygen, the hydroxyl radicals react with toluene to form benzyl alcohol, which is further combined with oxygen atoms in water to form benzaldehyde. Mo et al. ${ }^{35}$ found that the hydroxyl radicals react with toluene to have hydroxylation isomerism and this leads to the cracking of the benzene ring and the formation of small molecules chain. These substances then react with free hydroxyl radicals and hydrogen radicals to form formaldehyde and acetone. The experimental results are inconsistent with the conclusions by Huang et al. ${ }^{16}$ They believe that the formation of benzoic acid is an inevitable product of benzene ring cracking. However, benzoic acid is not detected under this medium condition, but opened loops of small molecules exist.

As shown in Fig. 8, the intermediate products of VUV degradation of toluene in aqueous air are benzene, formaldehyde, acetone, benzaldehyde and benzoic acid. All the reactions of toluene both with the aqueous air and atmosphere are similar. However, the difference is that the VUV radiation's dose and ozone's concentration are larger and higher. Many of the hydroxyl radicals found, but reaction with other pollutants $\left(\mathrm{NO}_{\mathrm{x}}\right)$ in the atmosphere were not found. Even though the reaction mechanisms of these two are similar, the difference in factors makes the final product different. Under the conditions of this experiment, the dehydrogenation reaction of toluene and hydroxyl forms benzyl group. While being oxidized by ozone, this group forms benzyl peroxy radical and two benzyl peroxy radicals, and is coupled to decompose and produce benzaldehyde and benzyl alcohol. ${ }^{36}$ Benzyl alcohol was not detected from the tail gas through this experiment. A probable explanation might be that benzyl alcohol was further oxidized to benzaldehyde by ozone. Benzaldehyde is further oxidized and forms benzoic acid by oxides such as ozone or a hydroxyl radical. Wu et al. ${ }^{31}$ also proposed that benzoic acid is able to remove carboxylic acid groups to form benzene under UV radiation, which is alternative to form benzene.

The decomposition of toluene through three different media conditions can be summarized as: (1) VUV photons can directly detoxify toluene to form benzene. (2) Hydroxyl radicals react with toluene through the dehydrogenation and addition process. (3) Ozone plays a crucial role in the formation of benzaldehyde and benzoic acid. Along with the hydroxyl radical action on toluene, there is a synergistic effect that is found. Ozone and high-energy photons result in stable intermediates such as benzoic acid and benzaldehyde and also other small molecules of formaldehyde and acetone. Due to the synergistic effect of experimental conditions on hydroxyl radicals, ozone, and high-energy photons, and power of the UV lamp, the intermediate products of toluene were barely detected in the decomposition process. The pathway of photodegradation of toluene is depicted in Fig. 9.

\section{Conclusions}

The photodegradation of toluene under VUV light sources was investigated under various experimental conditions; residence time, initial concentration, relative humidity, and degradation intermediates. In addition, the role of free radicals towards degradation of toluene was analyzed and the pathways for

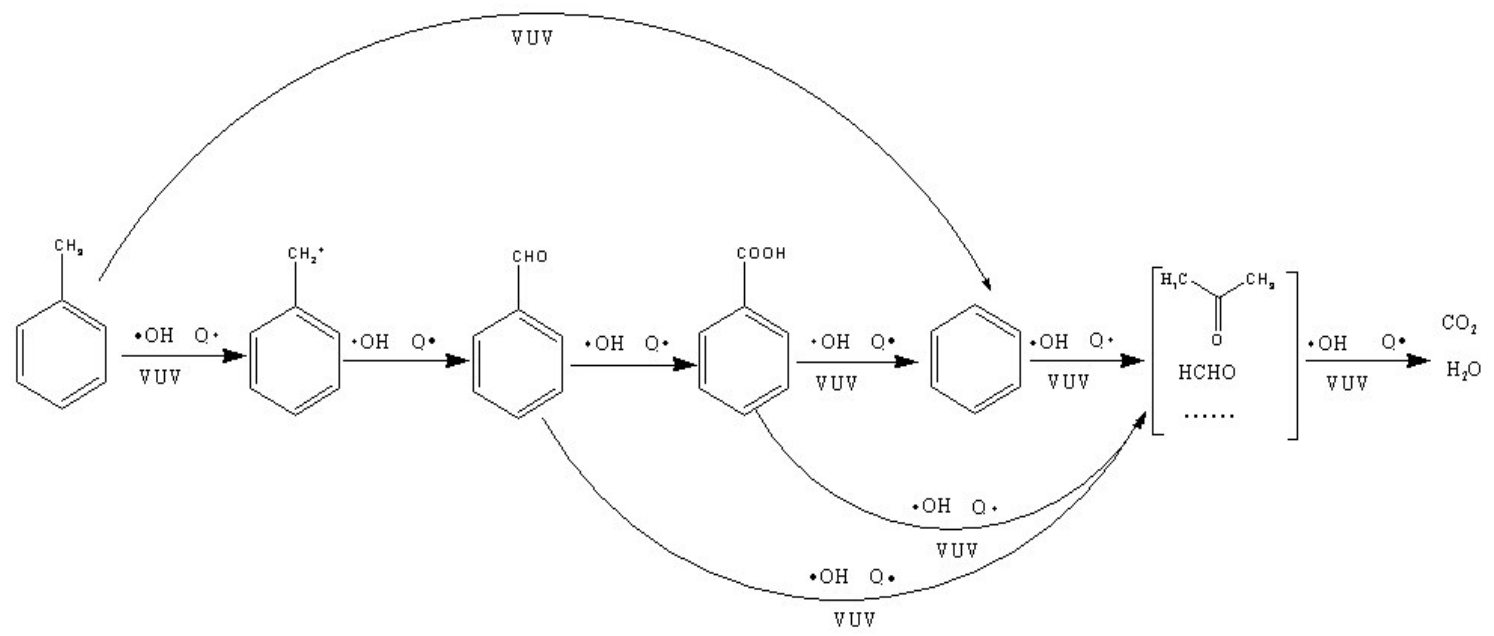

Fig. 9 The pathway of photodegradation of toluene with VUV process. 
photodegradation was established. This study provides a convenient way to process toxic toluene in air and has great potential for air pollution applications.

\section{Conflict of Interest}

There are no conflicts to declare.

\section{Acknowledgements}

This project is financially supported by the National Natural Science Foundation of China (51678353) and Cultivation Discipline Fund of Shanghai Polytechnic University (XXKPY1601). The authors also appreciate the Graduate Student Funding Program of Shanghai Polytechnic University (A10GY19H010-g18), and Gaoyuan Discipline of Shanghai Environmental Science and Engineering (Resource Recycling Science and Engineering).

\section{References}

1. M. Kampa and E. Castanas, Environ. Pollut., 2008, 151, 362-367.

2. L. Zhang, M. Qin, W. Yu, Q. Zhang, H. Xie, Z. Sun, Q. Shao, X. Guo, L. Hao, Y. Zheng and Z. Guo, J. Electrochem. Soc., 2017, 164, H1086-H1090.

3. S. Scirè and L. F. Liotta, Appl. Catal. B, 2012, 125, 222-246.

4. J. W. Hutchings and P. Herckes, AGU Mtg., 2009.

5. S. M. Murphy, J. Soltis, R. A. Field, T. S. Bates, P. Quinn, J. A. De Gouw, P. R. Veres, C. Warneke, M. Graus, J. Gilman, B. M. Lerner and A. Koss, AGU Mtg., 2013.

6. J. Jeong, K. Sekiguchi and K. Sakamoto, Chemosphere, 2004, 57, 663-671.

7. W. H. Glaze, J. W. Kang and D. H. Chapin, OZONE-SCI ENG, 1987, 9, 335352 .

8. I. Oller, S. Malato and J. A. Sánchez-Pérez, Sci. Total Environ., 2011, 409, 4141-4166.

9. C. Belver, M. A. J. López-Muñoz, J. M. Coronado and J. Soria, Appl. Catal. $B, 2003,46,497-509$

10. X. Huang, J. Yuan, J. Shi and W. Shangguan, J. Hazard. Mater., 2009, 171, $827-832$.

11. J. Peral and D. F. Ollis, J. Mol. Catal. A Chem., 1997, 115, 347-354.

12. E. Piera, J. A. Ayllón, X. Doménech and J. Peral, Catal. Today, 2002, 76, 259-270.

13. S. Peng, Y. Li, F. Jiang, G. Lu and S. Li, Chem. Phys. Lett., 2004, 398, 235-
239.

14. L. Rideh, A. Wehrer, D. Ronze and A. Zoulalian, Ind. Eng. Chem. Res., 1997, 36, 4712-4718.

15. C. H. Ao, S. C. Lee, J. Z. Yu and J. H. Xu, Appl. Catal. B, 2004, 54, 41-50.

16. H. Huang and W. Li, Appl. Catal. B, 2011, 102, 449-453.

17. C. Serralheiro, D. Duflot, F. F. da Silva, S. V. Hoffmann, N. C. Jones, N. J. Mason, B. Mendes and P. Limão-Vieira, J. Phys. Chem. A, 2015, 119, 90599069.

18. W. Zhao, Y. Yang, J. Dai, F. Liu and Y. Wang, Chemosphere, 2013, 91, $1002-$ 1008 .

19. H. Huang, H. Huang, L. Zhang, P. Hu, Y. Xu, X. Ye, X. Liang, J. Chen and M. Ji, Environ. Eng. Sci., 2014, 31, 481-486.

20. T. Alapi and A. Dombi, Chemosphere, 2007, 67, 693-701.

21. H. Huang, H. Huang, L. Zhang, P. Hu, X. Ye and D. Y. C. Leung, Chem. Eng. J., 2015, 259, 534-541.

22. J. Kim, P. Zhang, J. Li, J. Wang and P. Fu, Chem. Eng. J., 2014, 252, $337-$ 345 .

23. N. J. Turro, Modern molecular photochemistry, University science books, 1991.

24. T. Oda, Y. Yamashita, K. Takezawa and R. Ono, Thin. Solid Films, 2006, 506-507, 669-673.

25. A. H. Laufer and J. R. McNesby, J. Chem. Phys., 1968, 49, 2272-2278.

26. B. A. Thompson, P. Harteck and R. R. Reeves Jr, J. Geophys. Res., 1963, 68, 6431-6436.

27. K. Watanabe and M. Zelikoff, J. Opt. Soc. Am., 1953, 43, 753-755.

28. S. T. Amimoto, A. P. Force, R. G. Gulotty and J. R. Wiesenfeld, J. Chem. Phys., 1979, 71, 3640-3647.

29. K. H. Gericke and F. J. Comes, Chem. Phys. Lett., 1980, 74, 63-66.

30. L. C. Lee and T. G. Slanger, Geophys. Res. Lett., 1979, 6, 165-166.

31. R. Wu, S. Pan, Y. Li and L. Wang, J. Phys. Chem. A, 2014, 118, 4533-4547.

32. B. Trost, J. Stutz and U. Platt, Atmos. Environ., 1997, 31, 3999-4008.

33. Y. Zhan, J. Ji, H. Huang, M. He, D. Y. C. Leung, S. Liu, Y. Shu, Q. Feng, R. Xie, R. Fang and X. Ye, Chem. Eng. J., 2018, 334, 1422-1429.

34. R. Atkinson, Atmos. Environ., 2000, 34, 2063-2101.

35. J. Mo, Y. Zhang, Q. Xu, J. J. Lamson and R. Zhao, Atmos. Environ., 2009, 43, 2229-2246.

36. O. d'Hennezel, P. Pichat and D. F. Ollis, J. Photochem. Photobiol. A: Chem., 1998, 118, 197-204.

Publisher's Note Engineered Science Publisher remains neutral with regard to jurisdictional claims in published maps and institutional affiliations. 